\title{
Foreword
}

\section{Echocardiography 1995}

This is the second supplement produced by the British Society of Echocardiography in conjunction with the British Heart fournal. In this supplement we have tried to address issues relating to current practical applications of echocardiography and also to establish the value of emerging technologies which may or may not find a place in routine clinical practice in the future.

A consensus view of quantifying valvular regurgitation by echo Doppler has been provided by Simpson, together with a team of experienced coauthors from busy echocardiographic units throughout the country. We believe that this article, which stresses a multi-mode approach to quantifying valvular regurgitation, should be essential reading for all practising echocardiographers. The authors considered very carefully the role played by conventional spectral Doppler, colour flow mapping, and cross sectional imaging and have established guidelines for all four cardiac valves.

The clinical usefulness and cost effectiveness of intravascular ultrasound for study of the coronary anatomy and the morphology of coronary lesions remains to be established. The article by Kearney et al provides a detailed review of the current state of the art of this teçhnology. The authors have concentrated on the applications of intravascular ultrasound, examined the technological development of the technique, and performed a critical review of the evidence on its quantitative and qualitative accuracy. They have also carefully assessed the technique for potential clinical value and likely future developments. For those centres deciding upon whether or not to embark upon this fairly expensive technique, this article will provide an invaluable review. While the authors have clearly stressed the research potential of intravascular ultrasound, we suspect that many who would want it for its clinical purposes will decide to wait and see until the technology improves further and clear cost-benefit ratios have been established.

One of the more recent technological advances which will undoubtedly further extend the utility of intravascular ultrasound is the use of three dimensional reconstruction techniques. Salustri and Roelandt from the Thorax Centre have provided in their article a clear insight into the potential of three dimensional imaging of the coronary anatomy. It is interesting to note that several manu- facturers are now offering this facility as an additional feature on their intravascular ultrasound systems and therefore a review of the potential of this technology is timely. Three dimensional imaging of the coronary anatomy is a logical extension of conventional intravascular ultrasound techniques, although, as the authors have carefully explained, it is fraught with technical problems including cycle dependent movement of the arteries. Nevertheless, the greater the perspective that imaging techniques can provide on any part of the cardiac anatomy, the greater the diagnostic potential of the technique. Three dimensional imaging of the heart and the coronary arteries is here to stay.

Twenty one abstracts were presented at the British Society of Echocardiography autumn meeting held in November 1994 in Brighton. These abstracts are published in this supplement. They were all peer reviewed by reviewers who were blinded to the source of the abstract and in addition the reviewers did not receive abstracts from their own institution. The rejection rate was $40 \%$ and the consensus was that the abstracts and presented papers were of a high quality. Topics ranged from assessment of valve disease and prosthetic valves, transoesophageal and intravascular echo, stress echo, and evaluation of ventricular function. In addition, several papers were presented on audit of the use of echocardiographic services.

It is our intention to continue publishing this supplement on an annual basis and use it as a forum for presenting position papers and appropriate reviews on the use of echocardiography. In addition, we anticipate continuing to publish abstracts presented at our annual autumn meeting. We hope that you enjoy reading it and would welcome suggestions for future issues. In addition, we are indebted to Dr Peter Mills and his colleagues from the British Heart fournal for all their support and hard work which has made this project feasible.

$$
\begin{array}{r}
\text { M J MONAGHAN } \\
\text { President } \\
\text { P NIHOYANNOPOULOS } \\
\text { Chairman }
\end{array}
$$

Research and Scientific Subcommittee,

British Society of Echocardiography, 9 Fitzroy Square, London W1P 5AH 